\title{
Effect of curing temperature on the mechanical strength of alkali activated laterite geopolymeric samples
} \author{
Toutakhane ${ }^{4}$ \\ ${ }^{I}$ Department of Civil Engineering, Faculty of Engineering, University of Bonab, Iran \\ ${ }^{2}$ Graduate Student of Civil Engineering, University of Bonab, Iran \\ ${ }^{3}$ Researcher, University of Bonab, Iran \\ ${ }^{4}$ Department of Architecture, University of Bonab, Bonab, Iran \\ *E-mail: Fahmi.ahmad@ubonab.ac.ir; Corresponding Author.
}

Ahmad Fahmi ${ }^{1 *}$, Alireza Babaeian amini ${ }^{1}$, Yaser Marabi $^{2}$, Sohrab Rafati Zavaragh ${ }^{3}$ and Ali Majnouni-

Submitted: 18-09-2020

Revised: $10-10-2021$

Accepted: $28-10-2021$

\begin{abstract}
A huge amount of carbon dioxide is released in the Portland cement production process. A large quantity of greenhouse gases is produced because of the significant amount of energy consumption via making bricks through firing. Using the pozzolanic sources containing the aluminosilicate and alkaline reagents, a new type of green materials called geopolymeric materials is produced with quite lower environmental hazards. The use of laterite as an iron-rich aluminosilicate material has a high potential for the building materials. In this study, the effect of the curing temperature and characteristics of the alkaline reagent including the concentration of sodium hydroxide solution and the water-glass to sodium hydroxide mass mixing ratio on the mechanical strength of the lateritebased, oven-cured geopolymer samples was investigated. The results showed that the curing temperature had a significant effect on the compressive strength of the laterite-based geopolymer samples, so that with a $15^{\circ} \mathrm{C}$ change at the curing temperature, the compressive strength of the samples could be multiplied, and a sharp increase in the mechanical strength could occur. Also, according to the results of this study, the $6 \mathrm{M}$ sodium hydroxide is recommended for the construction of the laterite-based geopolymer materials with low cost and relatively high strength, and for the construction of higher-strength building materials, the $14 \mathrm{M}$ sodium hydroxide is recommended.
\end{abstract}

Keywords: Geopolymer; Laterite; Alkali activated; Curing Temperature; Mechanical strength.

\section{INTRODUCTION}

To produce one ton of Portland cement, a bit less than one ton of carbon dioxide is released [1,2]. About $5-7 \%$ of the carbon dioxide produced in the world is related to the Portland cement industry [3,4]. After concrete, brick is the second most widely used construction material [5]. A large quantity of greenhouse gases is produced because of the significant amount of energy consumption via making bricks through firing [6-8]. Using the chemical reaction of the alkaline reagents such as sodium hydroxide and sodium silicate solutions with solid aluminosilicate compounds, it is possible to produce the environmentally friendly cement (or binder) called geopolymer. If geopolymeric cement and materials are replaced with (some part of) the conventional building materials such as Portland cement concrete and fired brick, the amount of greenhouse gases is significantly reduced $[2,9,10]$.

The high mechanical strength, low shrinkage, high durability against acid, fire and various environmental conditions, and low thermal exchange are among the advantages of geopolymer materials [9, 11]. Geopolymers are strong and durable cementitious materials, which are capable of hardening and polycondensation at the temperatures lower than $100{ }^{\circ} \mathrm{C}[12]$. The aluminosilicate base used to produce geopolymer can include the natural 
resources such as volcanic ash, kaolinite and laterite, artificial aluminosilicates, and various industrial waste such as brick and concrete waste powders, fly ash, furnace slag, rice husk ash, and palm oil fuel ash [13-19].

Natural laterite is the composite material of iron, aluminum, and silicon [20]. Among others, the use of laterite as an iron-rich aluminosilicate material has a high potential for the building materials.

The firing of non-geopolymer laterite bricks (without the use of alkaline reagent) at various temperatures was investigated by Mbumbia, de Wilmars [21]. The mixture of laterite with $\mathrm{Ca}(\mathrm{OH})_{2}$ in the autoclave as well as the laterite mixture with Portland cement can also be used to produce the building blocks [22]. The high content of iron oxides and hydroxides and presence of alumina and silica make it possible to use sustainable and low-cost silica source to produce complex composites with a high fraction of ferrisilicates, through geopolymerization process. Curing of samples in temperature $50-100{ }^{\circ} \mathrm{C}$ makes it possible to enhance the transformation of hydrates and oxyhydrates to ferrisilicates in addition to the formation of ferrosialates and polysialates [23].

The laterite geopolymer products are classified as green, environmentally friendly, and sustainable products [24]. Laterites are abundant throughout the globe and could be assumed as consistent precursor for geopolymers [3]. In the field of geopolymers, various studies have been conducted on the production of lateritebased geopolymer samples, and their setting time and mechanical properties have been investigated [21, 25, 26]. Also, the phosphoric acid and alkaline reagents were separately studied for the production of geopolymer samples with the laterite aluminosilicate source (laterite soil) by Gualtieri, Romagnoli [25]. The improvement of laterite soil using the alkaline stabilizing solution has also been investigated [27, 28].

Temperature and time are two important parameters influencing the strength of geopolymer materials [9]. It is possible to obtain building materials such as bricks hardened at room temperature or ceramic bricks with maximum heating from $85^{\circ} \mathrm{C}$ to $450^{\circ} \mathrm{C}$ [22]. The effect of these parameters on the geopolymer samples based on the fly ash, metakaolin, and other aluminosilicate precursors has been investigated [29-31]. Oven-cured geopolymers gain their maximum strength at early ages (unlike the ambient-cured geopolymers) [32]. The present study explores the mechanical strength of the different laterite-based geopolymer samples cured in oven. The effects of curing temperature in the range of $25-100{ }^{\circ} \mathrm{C}$ with different molarities of sodium hydroxide solution on the 3-and 7-day compressive strengths of the samples were considered. The research challenge in this study is the effect of increasing the curing temperature on the change of mechanical strength of the laterite based geopolymer samples.

\section{MATERIALS AND METHODS}

\section{MATERIALS}

The aluminosilicate base material used in this study for the production of the geopolymer sample is the laterite rock powder. Laterite rock was provided from Ghar-Yaghdi laterite-bauxite deposit of Miandoab, Iran. Based on the results of the XRF analysis, the oxide compounds existing in the laterite rock powder are presented according to Table 1. This iron-rich material as an aluminosilicate source for making geopolymer samples has relatively low silica in the comparison with other aluminosilicate custom materials. To prepare the alkaline solution for preparation of laterite-based geopolymer samples, sodium hydroxide ( $99 \%$ caustic soda flakes), water (drinking water from Bonab, Iran), and commercial water-glass of 2.5 ratio (specifications according to Table 2 ) were used. Some $5 \times 5 \times 5 \mathrm{~cm}$ cubic molds, $16 \times 4 \times 4 \mathrm{~cm}$ prismatic molds, and standard briquette (dumbbell-shaped) molds were used to prepare geopolymer samples to evaluate the compressive, flexural, and tensile strength of the samples, respectively (all used molds were triplex). The equipment used in this study includes a laboratory chemical hood for preparing the alkaline solutions, a pan mixer, and a vibrating device (table) for preparing of the samples and oven for their curing. Also, uniaxial compression testing device for measurement of the compressive strength and dual-purpose testing machine for measurement of the flexural and tensile strength of the cured samples were used.

Table 1. Chemical composition (oxide compounds) of laterite rock powder based on XRF analysis.

\begin{tabular}{|l|l|l|l|l|l|l|l|l|l|l|l|l|}
\hline $\mathrm{K}_{2} \mathrm{O}$ & $\mathrm{CoO}$ & $\mathrm{MnO}$ & $\mathrm{SO}_{3}$ & $\mathrm{P}_{2} \mathrm{O}_{5}$ & $\mathrm{CaO}$ & $\mathrm{V}_{2} \mathrm{O}_{5}$ & $\mathrm{Cr}_{2} \mathrm{O}_{3}$ & $\mathrm{MgO}$ & $\mathrm{TiO}_{2}$ & $\mathrm{Fe}_{2} \mathrm{O}_{3}$ & $\mathrm{SiO}_{2}$ & $\mathrm{Al}_{2} \mathrm{O}_{3}$ \\
\hline 0.04 & 0.07 & 0.08 & 0.08 & 0.09 & 0.47 & 0.15 & 0.13 & 1.64 & 2.89 & 32.8 & 16.7 & 32.5 \\
\hline
\end{tabular}


Table 2. Specifications of used water-glass.

\begin{tabular}{|c|c|}
\hline Ratio & 2.5 \\
\hline $\mathrm{Na}_{2} \mathrm{O} \%$ & $13-13.89$ \\
\hline $\mathrm{SiO}_{2} \%$ & $32.59-34.64$ \\
\hline
\end{tabular}

\section{TEST DESIGN OF LATERITE BASED GEOPOLYMER SAMPLES}

The laterite rock was crushed in the crusher machine, and the laterite rock powder passing the sieve No. 30 was selected as a solid aluminosilicate base material. The $6,10,14$, and 18 molar sodium hydroxide solutions were used to produce the laterite based geopolymer samples. To prepare the alkaline reagent solution, the waterglass to sodium hydroxide mass mixing ratio was selected as 1 or 2. For example, the G10-2 geopolymer sample indicates the use of $10 \mathrm{M}$ sodium hydroxide solution and the water-glass to sodium hydroxide solution mass mixing ratio of 2 .

The mix design for the geopolymer cubic samples is shown in Table 3 . The mass values presented in the table are those of materials needed to produce a cubic $5 \times 5 \times 5$ sample. For all samples, the weight ratio of alkaline solution to laterite powder was selected as 0.25 . Eight alkaline solutions with different molarities of sodium hydroxide and weight ratios of water-glass to sodium hydroxide solution were used. For preparing the cubic laterite-based geopolymer samples with 8 different alkaline solutions in 6 curing temperature ranges $(25,40,55$, 70,85 , and $100^{\circ} \mathrm{C}$ ) and two different ages ( 3 days and 7 days), $8 \times 6 \times 2=96$ test designs were planned. For each test design, three replications (for measuring the average strength for each composition design) and thus a total of 288 cubic samples were prepared.

Table 3. Mix design of geopolymer cubic samples cured at 6 different temperatures $(25,40,55,70,85$, and 100 $\left.{ }^{\circ} \mathrm{C}\right)$.

\begin{tabular}{|c|c|c|c|c|c|c|c|c|}
\hline \multirow[b]{2}{*}{ No. } & \multirow[b]{2}{*}{ Sample } & \multirow[b]{2}{*}{$\begin{array}{c}\mathrm{NaOH} \\
\text { Solution } \\
\text { Molarity }\end{array}$} & \multirow{2}{*}{$\begin{array}{l}\text { Mass mixing } \\
\text { ratio of } \mathrm{NaOH} \\
\text { Solution to } \\
\text { Water-Glass }\end{array}$} & \multicolumn{3}{|c|}{ Mass of Materials (gr) } & \multirow[b]{2}{*}{$\begin{array}{l}\text { Weight Ratio } \\
\text { of alkaline } \\
\text { solution to } \\
\text { Laterite } \\
\text { Powder }\end{array}$} & \multirow[b]{2}{*}{$\begin{array}{l}\text { Number } \\
\text { of } \\
\text { Samples }\end{array}$} \\
\hline & & & & $\begin{array}{l}\text { Laterite } \\
\text { Powder }\end{array}$ & $\begin{array}{c}\mathrm{NaOH} \\
\text { Solution }\end{array}$ & $\begin{array}{l}\text { Water- } \\
\text { Glass }\end{array}$ & & \\
\hline 1 & G 6-1 & 6 & 1 & 250 & 31 & 31 & 0.25 & $3 \times 2 \times 6$ \\
\hline 2 & G 6-2 & 6 & 2 & 250 & 21 & 41 & 0.25 & $3 \times 2 \times 6$ \\
\hline 3 & G 10-1 & 10 & 1 & 250 & 31 & 31 & 0.25 & $3 \times 2 \times 6$ \\
\hline 4 & G 10-2 & 10 & 2 & 250 & 21 & 41 & 0.25 & $3 \times 2 \times 6$ \\
\hline 5 & G 14-1 & 14 & 1 & 250 & 31 & 31 & 0.25 & $3 \times 2 \times 6$ \\
\hline 6 & G 14-2 & 14 & 2 & 250 & 21 & 41 & 0.25 & $3 \times 2 \times 6$ \\
\hline 7 & G 18-1 & 18 & 1 & 250 & 31 & 31 & 0.25 & $3 \times 2 \times 6$ \\
\hline 8 & G 18-2 & 18 & 2 & 250 & 21 & 41 & 0.25 & $3 \times 2 \times 6$ \\
\hline
\end{tabular}


For preparing the prismatic laterite-based geopolymer samples with 8 different alkaline solutions in curing temperature of $70{ }^{\circ} \mathrm{C}$ and two different ages ( 3 days and 7 days), $8 \times 1 \times 2=16$ test designs were planned. For each test design, three replications and thus a total of 48 prismatic samples were prepared. Similarly, 16 test designs for briquette geopolymer samples (totally 48 samples) were prepared too. The mass of consumed materials for each prismatic sample is 2.05 -fold, and that for each briquette sample is 0.52 -fold of the cubic samples (according to table 3 ).

\section{PREPARATION AND CURING OF LATERITE BASED GEOPOLYMER SAMPLES}

For preparing the samples of each test design according to the mentioned composition designs, according to Table 3, the required amount of laterite powder was poured into the plastic container, and the required amount of specified alkaline solution was gently added and mixed (care should be taken that the mixing of the materials should never be done in the metal containers). The materials were then poured into the pan mixer, and after 5 minutes of complete mixing, the materials were poured into the molds and vibrated on a vibrating device. All samples after the initial setting and removal from the mold were stored in oven at a specified temperature for 3 days.

\section{MEASUREMENT OF THE MECHANICAL STRENGTH}

After leaving the oven and cooling, the 3-day mechanical strength of the specified geopolymer samples was measured, and the average mechanical strength of three samples of each test design was calculated. Other oven-cured geopolymer samples (for evaluating the 7-day mechanical strength) were kept at ambient temperature for 4 days, and the 7-day mechanical strength of the samples was measured, and the average mechanical strength of three samples of each test design was calculated. The compressive strength of the cubic samples was measured by the uniaxial compression testing device. The flexural strength of the prismatic samples was measured using 3point-bending method. The flexural and tensile strengths of the prismatic and briquette samples were measures using a special multipurpose device.

\section{X-RAY FLUORESCENCE (XRF)}

The dried laterite powder pressed to tablets with boric acid as additive to determine the elemental composition with S4 EPLORER X-ray fluorescence spectrometer.

\section{X-RAY DIFFRACTION (XRD) ANALYSIS}

XRD analysis in the angular region $(2 \theta)$ of $15-80^{\circ}$ was recorded by X'pert Pro diffractometer (Panalytical, Netherland) with $\mathrm{Cu}$ anode, at room temperature, step size of $0.026^{\circ}$, a rate of $1 \%$ min, a wavelength of $0.154056 \mathrm{~nm}, 40 \mathrm{kV}$, and $40 \mathrm{~mA}$. XRD analysis was performed for laterite powder and powdered geopolymer samples including G6-1, G10-1, G14-1, and G18-1 cured at $85^{\circ} \mathrm{C}$.

\section{FE-SCANNING ELECTRON MICROSCOPY (FESEM) AND ENERGY-DISPERSIVE X-RAY (EDX)}

FE-scanning electron microscopy analyses of Laterite rock sample, Laterite rock sample, and geopolymer samples (G6-1, G10-1, and G14-1, G18-1 cured at $85{ }^{\circ} \mathrm{C}$ ) were scanned at room temperature and $20 \mathrm{kV}$ with FESEM microscope. The EDXs were recorded for samples and elements of $\mathrm{Si}, \mathrm{Al}, \mathrm{Fe}, \mathrm{Na}$, and $\mathrm{O}$ and were considered.

\section{RESULTS AND DISCUSSION}

\section{COMPRESSIVE STRENGTH}

The 3- and 7-day compressive strengths of the geopolymer samples are shown in Fig. 1. The compressive strength is the same as average compressive strength of 3 samples of each test setup. The 3- and 7-day compressive strengths of all samples cured at 25 and $40{ }^{\circ} \mathrm{C}$ (near the ambient temperature) are less than $10 \mathrm{MPa}$. Also, the 3and 7-day compressive strengths of the cured samples at $70-100{ }^{\circ} \mathrm{C}$ are above $10 \mathrm{MPa}$ (10 to $57 \mathrm{MPa}$ ). Particularly, 
the compressive strength above $20 \mathrm{MPa}$ is often achieved at 85 and $100{ }^{\circ} \mathrm{C}$. Therefore, in summary, it can be concluded that, to bring the compressive strength of the geopolymer samples based on the laterite (used in this research) to the values above 10 and $20 \mathrm{MPa}$, it is necessary to cure the samples at a temperature range of 70-100 ${ }^{\circ} \mathrm{C}$ in the oven, and at a lower temperature (near the ambient temperature), a less compressive strength is achieved. Therefore, to prepare the high-strength geopolymer building materials based on the laterite, it is necessary to use the oven, and this is also confirmed by the results of various studies performed in the field of geopolymer [33].

Also, according to Fig. 1, in the geopolymer samples produced by $6 \mathrm{M}$ sodium hydroxide (G6-1, G6-2) with the minimum use of alkaline reagents at the curing temperature of $85{ }^{\circ} \mathrm{C}$, the 3 -day compressive strength above $20 \mathrm{MPa}$ was obtained. Therefore, the use of the mentioned test setups (G6-1, G6-2) for the production of building materials such as engineering bricks and precast components is important from three viewpoints: low cost, relatively good mechanical strength, and early strength (compressive strength of samples reaching to desirable values in a short 3-day period).
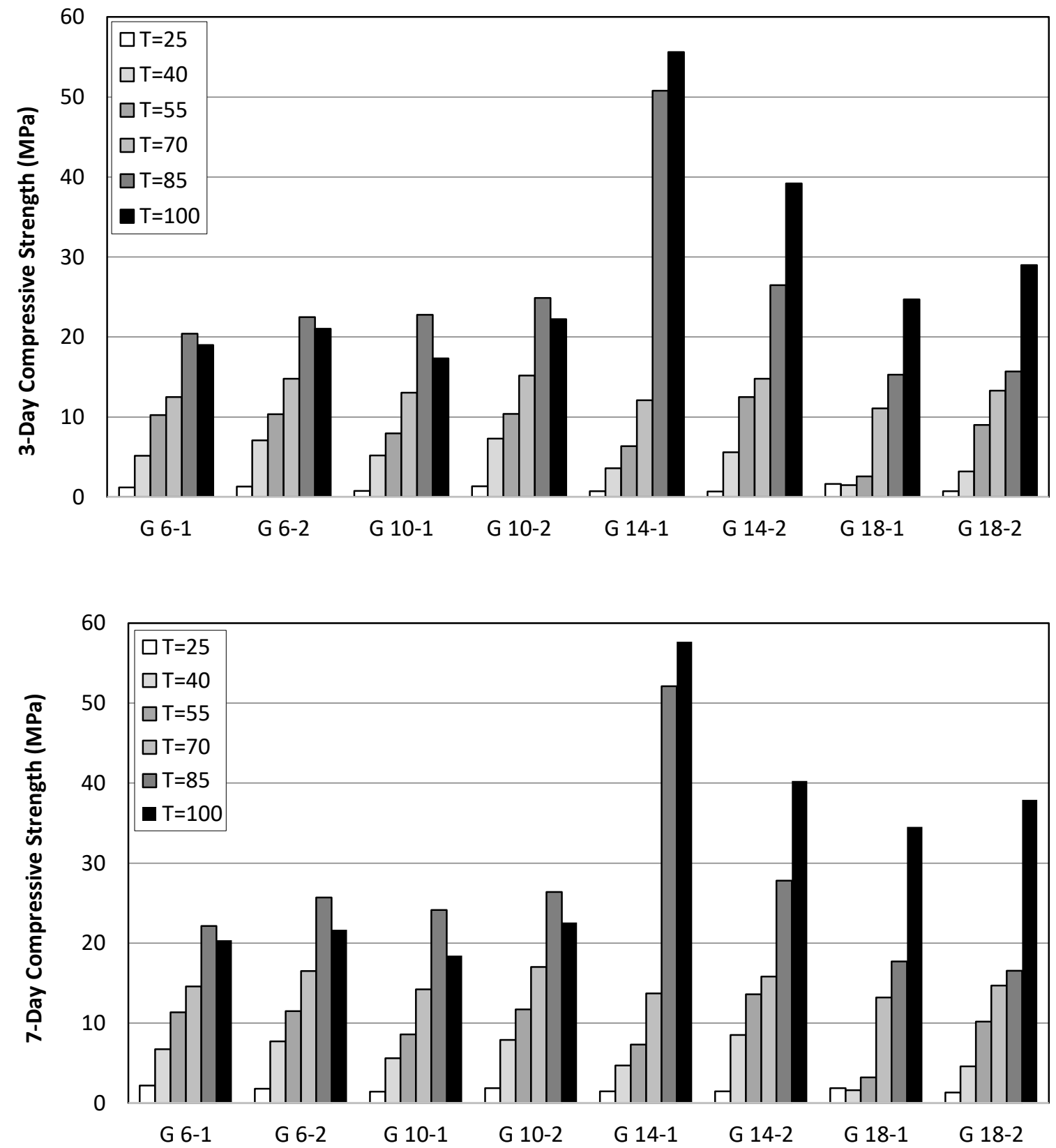

Fig. 1. Average 3-day (upper diagram) and 7-day (lower diagram) compressive strengths of geopolymer samples cured at various temperatures. 
The results of studies in the field of geopolymer produced by fly ash show that, by increasing the sodium hydroxide molarity, the compressive strength of the samples is increased, and the highest compressive strength of the samples was obtained for the use of $12 \mathrm{M}$ sodium hydroxide, and the samples prepared with higher molarity had less compressive strength [30, 34-36]. However, according to the results of this study, for the laterite-based geopolymer samples, the maximum compressive strength of the samples was obtained using the $14 \mathrm{M}$ sodium hydroxide.

As shown in Fig. 1, for the geopolymer samples produced using the alkaline reagent solution containing $14 \mathrm{M}$ sodium hydroxide and the water-glass to sodium hydroxide solution mass mixing ratio equal to 1 (samples G14-1) at 85 and $100{ }^{\circ} \mathrm{C}$, the 3-day compressive strength values of the geopolymer samples are higher than 50 $\mathrm{MPa}$, and therefore, the high-strength precast components can be produced by the geopolymer samples with the specified characteristics (samples G14-1). Various studies have emphasized the necessity to use the geopolymer technology for the construction of precast components with high mechanical strength [37, 38]. The amount of alkaline sodium hydroxide used in the construction of samples G14-1 is more than 2 times the samples G6-1, while the compressive strength of the samples is increased more than 2 times. It should be noted, however, that, with higher use of alkaline reagent (samples G18-1), the compressive strength will be decreased. Therefore, for the construction of geopolymer construction materials based on the laterite (laterite used in this research) at low cost and relatively high strength, the use of $6 \mathrm{M}$ sodium hydroxide is recommended, and for the construction of higherstrength building materials, it is recommended to use $14 \mathrm{M}$ sodium hydroxide.

According to Fig. 1, by increasing the curing temperature from 70 to $85^{\circ} \mathrm{C}$, the 3 -day compressive strength of samples G14-1 considerably increased from 12.1 to $50.8 \mathrm{MPa}$ (320\% increase), and the 7-day strength of the same samples was significantly increased from 13.7 to $52.1 \mathrm{MPa}$ ( $280 \%$ increase). These sharp increases in the compressive strength values were obtained only with $15^{\circ} \mathrm{C}$ increase in the curing temperature.

In the studies on the geopolymer concrete produced by fly ash, the compressive strength of the samples was also increased by increasing the time and age of the samples and also increasing the curing temperature from 10 to $80{ }^{\circ} \mathrm{C}$ (as well as from 60 to $90{ }^{\circ} \mathrm{C}$ ) [29, 39]. In the metakaolin-based geopolymer samples, by increasing the curing temperature from 15 to $60{ }^{\circ} \mathrm{C}$, the compressive strength of the samples was increased, and with a further increase in the curing temperature, the compressive strength was reduced [24]. However, according to the results of the present study, for the laterite-based geopolymer samples, as shown in Fig. 1, for the prepared samples produced by sodium hydroxide concentration of 8 and $10 \mathrm{M}$, with the continuous increase in the curing temperature from 25 to $85{ }^{\circ} \mathrm{C}$, the compressive strength of the geopolymer samples was increased, but by increasing the temperature from 85 to $100{ }^{\circ} \mathrm{C}$, the compressive strength showed a decreasing trend. However, for the samples with the 14 and $18 \mathrm{M}$ concentration of sodium hydroxide, by increasing the temperature from 25 to $100{ }^{\circ} \mathrm{C}$, the compressive strength of the geopolymer samples is constantly increased and does not show a decreasing trend.

According to the results of this study, in the laterite-based geopolymer samples, according to Fig. 2, by increasing the curing temperature from 85 to $100{ }^{\circ} \mathrm{C}$ in some samples, the increased compressive strength is achieved, and in some other samples, the compressive strength is reduced. In other words, the mechanical behavior of laterite-based geopolymer samples varies with the concentration of the alkaline solution (sodium hydroxide molarity) and the curing temperature.

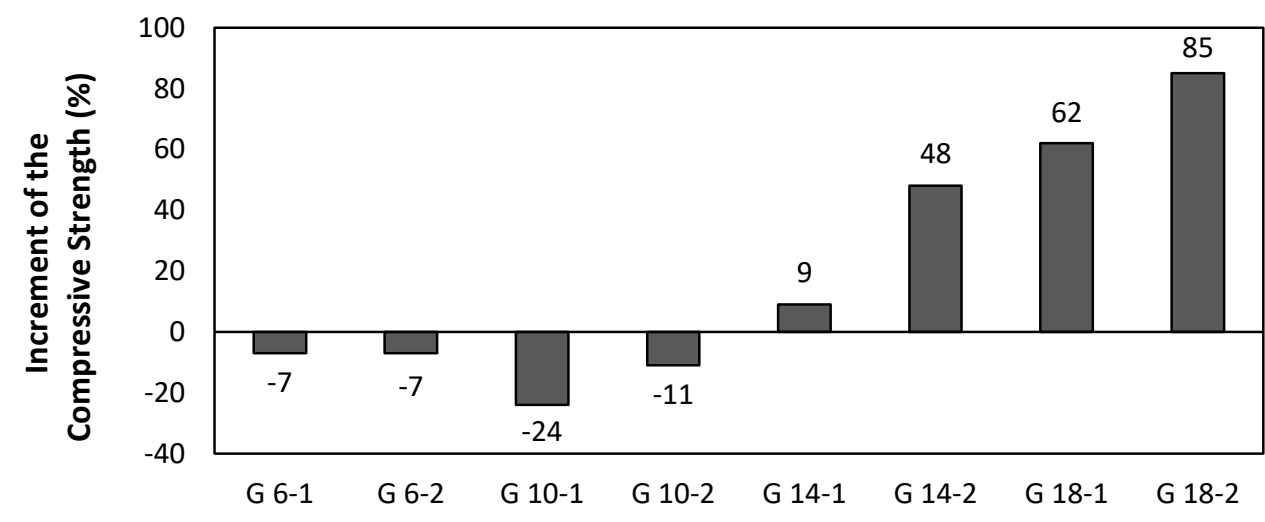

Fig. 2. Increase in 3-day compressive strength of different geopolymer samples due to increase in curing temperature from 85 to $100{ }^{\circ} \mathrm{C}$. 
Also, according to Fig. 3, by the $60^{\circ} \mathrm{C}$ increase in the curing temperature of the samples from 40 to 100 ${ }^{\circ} \mathrm{C}$, the compressive strength of the geopolymer samples with 6 and $10 \mathrm{M}$ sodium hydroxide was increased from 196 to $270 \%$, and for the samples with 14 and $18 \mathrm{M}$ sodium hydroxide, it was increased from 600 to $1570 \%$. Specifically, this increase in the samples with the water-glass to sodium hydroxide solution ratio of 1 considerably varies between 1445 and $1570 \%$.

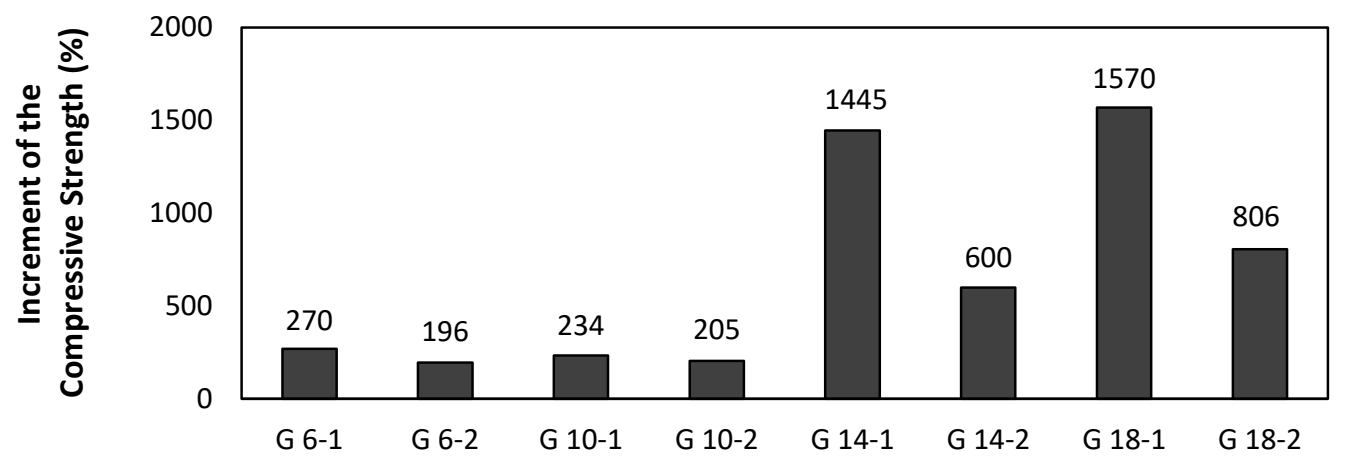

Fig. 3. Increase in 3-day compressive strength of different geopolymer samples due to increase in curing temperature from 40 to $100{ }^{\circ} \mathrm{C}$.

Also, comparing the 3- and 7-day compressive strength values of cured geopolymer samples in the temperature range $25-100{ }^{\circ} \mathrm{C}$ (Fig. 4) shows that the difference percentage of 3- and 7-day compressive strengths in the samples produced by the 6-14 M sodium hydroxide is insignificant, and there is only a significant difference in the samples produced by the $18 \mathrm{M}$ sodium hydroxide. However, for the $25^{\circ} \mathrm{C}$ curing temperature in all the samples, the difference percentage of 3- and 7-day compressive strengths is not low.
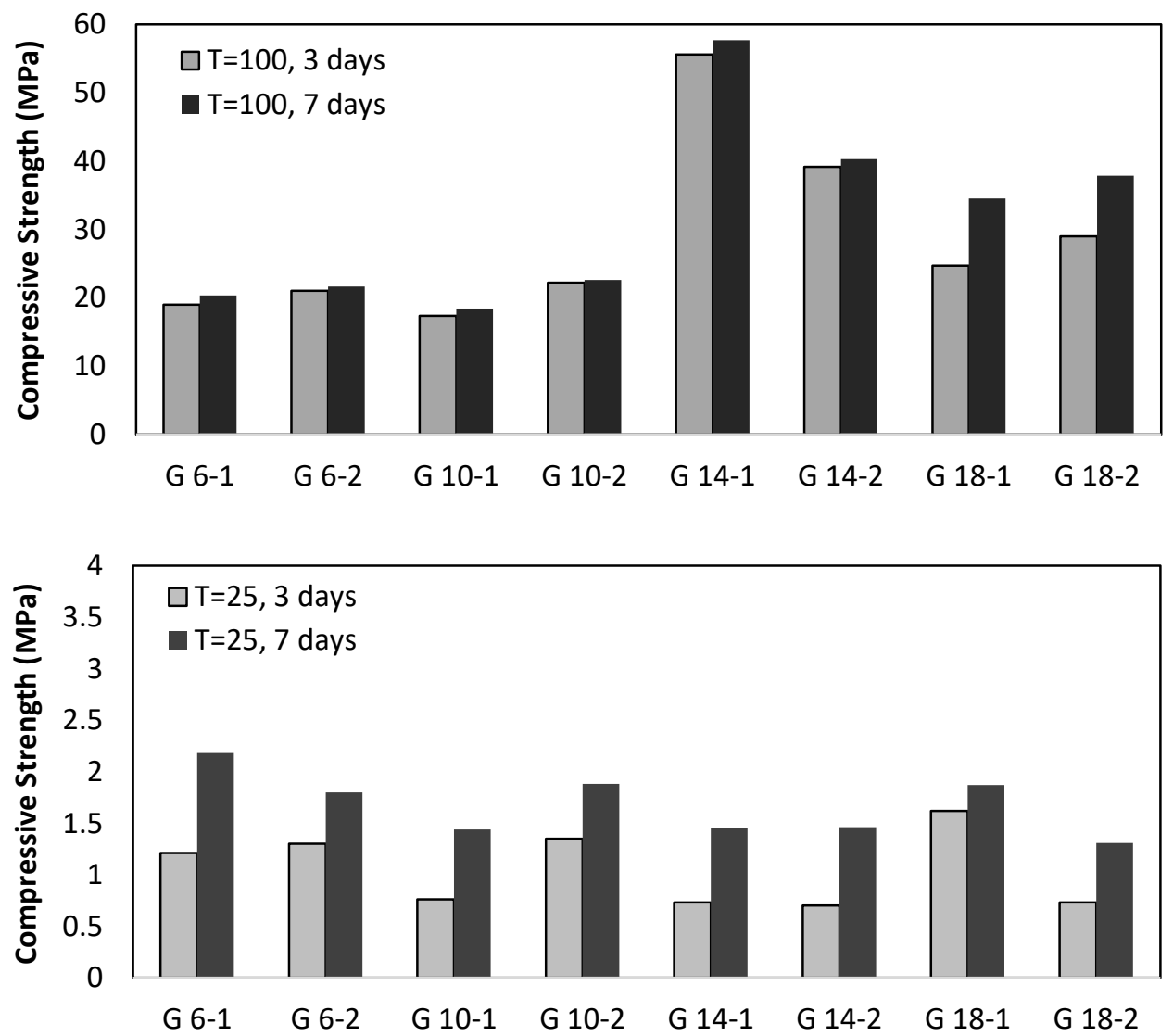

Fig. 4. 3- and 7-day compressive strengths of geopolymer samples at $100{ }^{\circ} \mathrm{C}$. 


\section{FLEXURAL AND TENSILE STRENGTH}

The 3- and 7-day flexural and tensile strengths of the geopolymer samples (cured at $70^{\circ} \mathrm{C}$ ) are shown in Fig. 5. Similar to the results of the compressive strength, the highest amounts of the flexural and tensile strength belonged to G 14-1 samples. The flexural and tensile strengths of the samples G 6-1 and G 14-1 samples do not have much difference; so from the aspect of economics, for making of the geopolymer samples, using the lower molarity $(6 \mathrm{M})$ of sodium hydroxide is preferable. For extremely high strength class $\mathrm{F}$ fly ash geopolymer mortar, the flexural strength of samples, at $72 \mathrm{~h}$ heat curing in $75^{\circ} \mathrm{C}$, was reported between 5.2 and $12.9 \mathrm{MPa}$ [40]. In this research, flexural strength increases with $\mathrm{Na}(\%)$ increment, and for more increment, the flexural strength decreases [40], so these results for F fly ash geopolymer mortar are in accordance with our results for laterite based geopolymer samples.
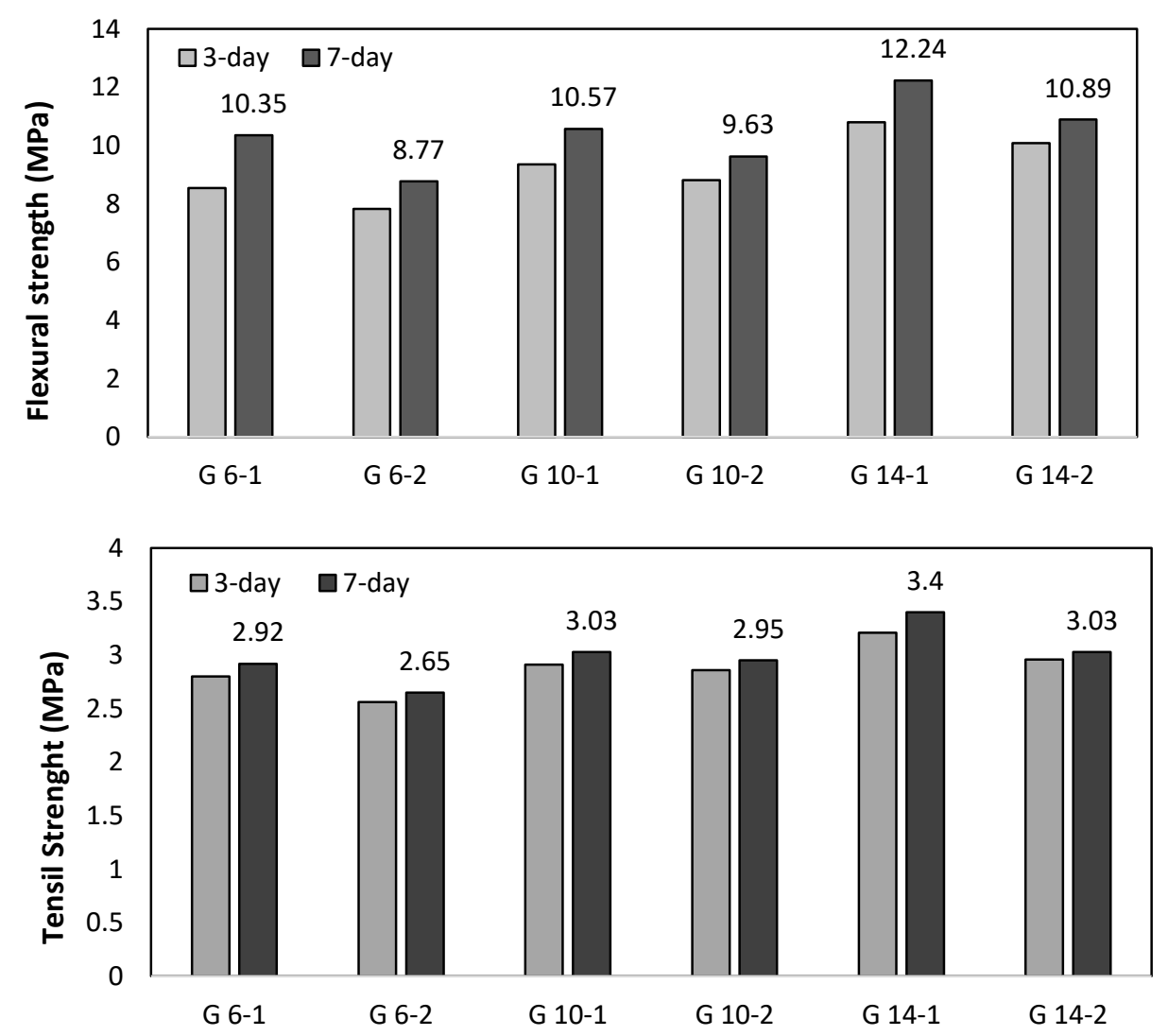

Fig. 5. 3- and 7-day flexural and tensile strengths of geopolymer samples, cured at $70{ }^{\circ} \mathrm{C}$.

\section{FESEM, EDX, AND XRD ANALYSIS}

FESEM and EDAX analyses of laterite rock sample and laterite-based geopolymeric samples G10-1 and G14-1 cured at $85{ }^{\circ} \mathrm{C}$ are done as shown in Fig. 6. For laterite rock sample, no picks related to Na element were recognized. But, in geopolymeric samples, Na element was recognized. The weight percent of Na in G10-1 sample and G14-1 sample was reported to be 9 and $19 \%$, respectively.

SEM examination of Laterite rock (A), Laterite grinded powder (B), geopolymer sample G6-1 (C), geopolymer sample G10-1 (D), geopolymer sample G14-1 (E), and geopolymer sample G18-1 (F) at 10000x magnification is done as shown in Fig. 7. Comparison of the FESEM examination of Laterite rock (A) with Laterite grinded powder (B) shows that after grinding the structure of material was partly changed, FESEM examination of geopolymer samples (C-D) shows that the structure of geopolymer samples in the comparison the laterite base materials (A \& B) completely was changed. Also, for increment of sodium hydroxide molarity (C to D), the porosity of geopolymer samples was decreased. 

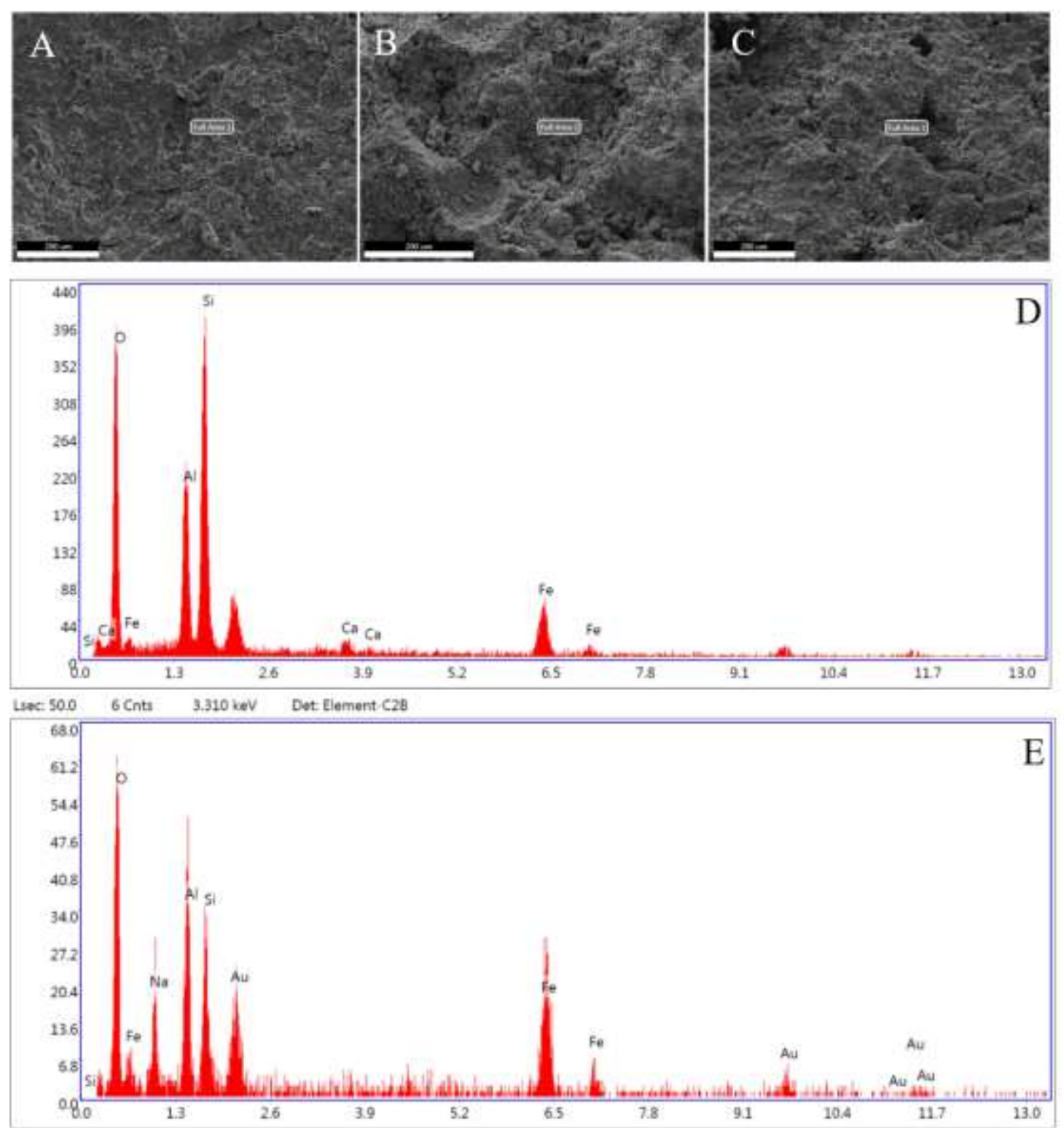

Lsec:29.4 $29 \mathrm{Cnts} 1720 \mathrm{keV}$ Det Element-C28

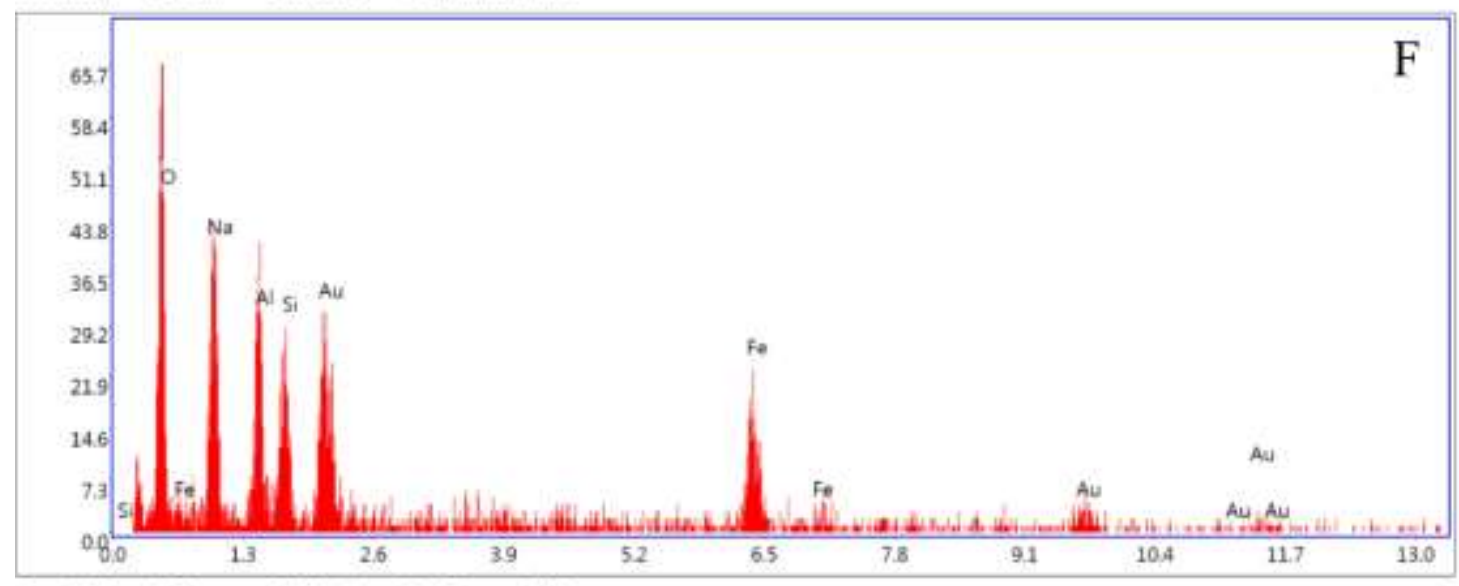

Lsec 39.2 1 Cntr $3.510 \mathrm{keV}$ Det Eement-C2B

Fig. 6. A,C (FESEM and EDAX of laterite rock sample), B,D (FESEM \& EDAX of G10-1 sample), and E,F (FESEM and EDAX of G14-1 sample). 

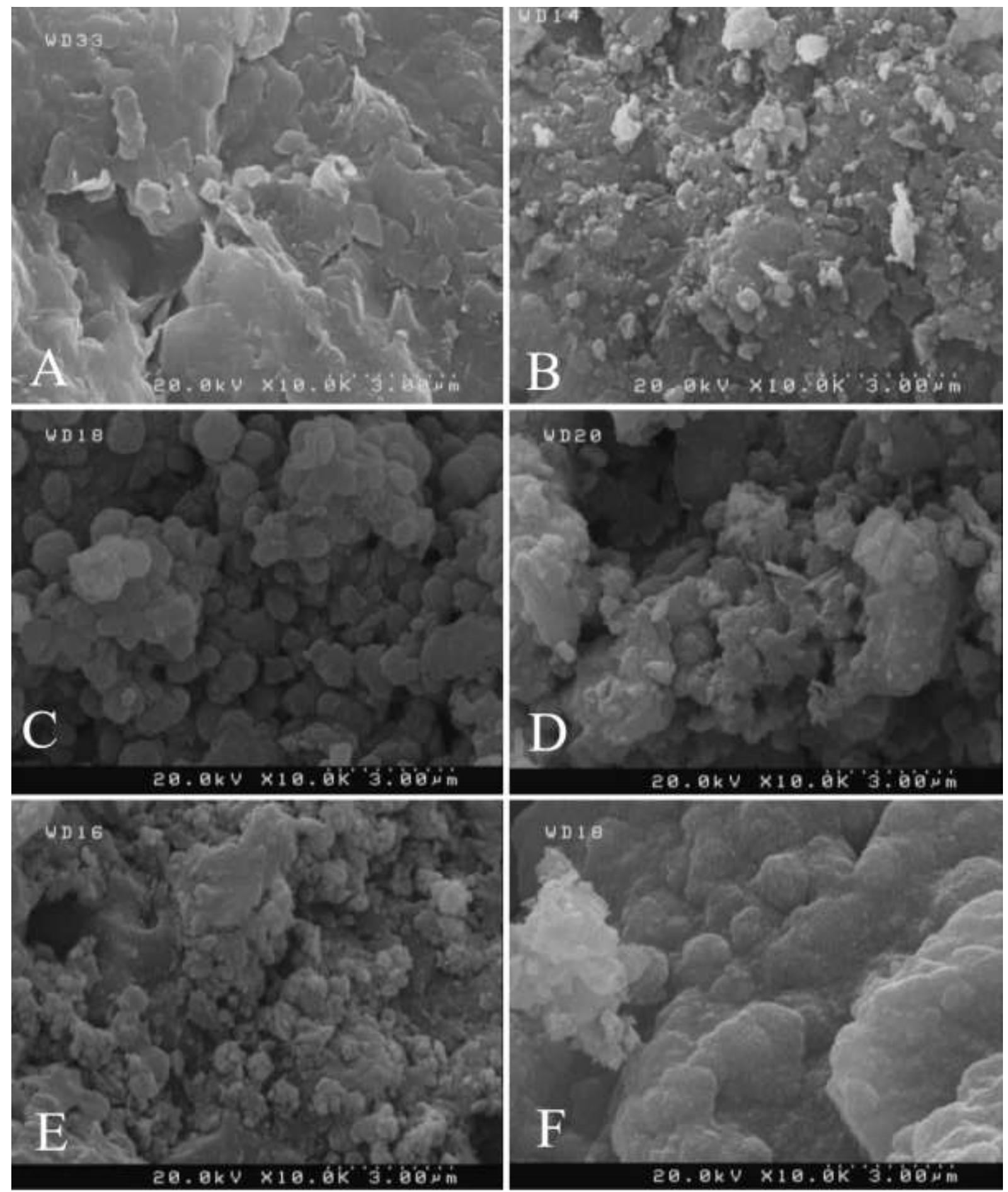

Fig. 7. SEM examination of Laterite rock (A), Laterite grinded powder (B), geopolymer sample G6-1 (C), geopolymer sample G10-1 (D), geopolymer sample G14-1 (E), and geopolymer sample G18-1 (F) at 10000x magnification.

According to XRD analysis, the Laterite rock powder consisted of Kaolinite (Aluminum Hydroxide Silicate), Hematite (Iron Oxide), and Cristobalite (Silicon Oxide) minerals. According to Fig. 8, in the geopolymeric samples, the picks related to these minerals changed more with the increment of the concentration (molarity) of sodium hydroxide, so that, in G18-1, the change of picks is significant. 


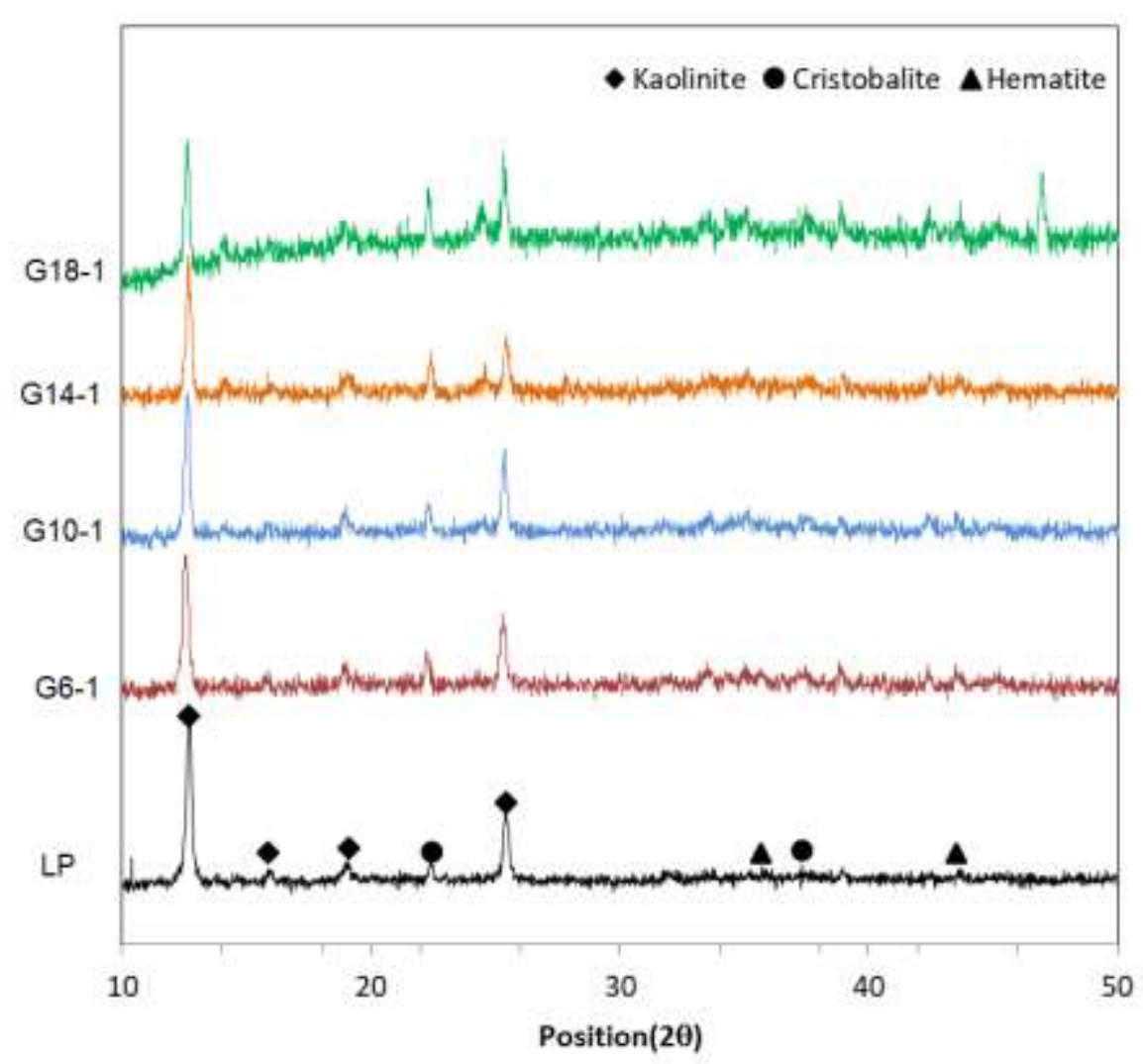

Fig. 8. XRD analysis of Laterite powder (LP) and geopolymeric samples G6-1, G10-1, G14-1, and G18.-1

\section{CONCLUSION}

The results of the present study show that the curing temperature has a significant effect on the compressive strength of the laterite-based, oven-dried geopolymer samples, and the compressive strength of the samples can be sharply increased by the $15^{\circ} \mathrm{C}$ change in the curing temperature, and a sharp increase can occur in the mechanical strength. The compressive strength of the geopolymer samples can be increased over $20 \mathrm{MPa}$ and even over $50 \mathrm{MPa}$ over 3 days, and thus, it is possible to be used in the building materials such as engineering bricks and high-strength precast components. Also, the molar concentration of sodium hydroxide solution and the water-glass to sodium hydroxide solution mass mixing ratio have a significant effect on the mechanical strength of the laterite-based geopolymer samples. Similar to the results of the compressive strength, the highest amounts of the flexural and tensile strength belonged to $\mathrm{G}$ 14-1 samples. The flexural and tensile strengths of the samples G 6-1 and G 14-1 samples do not have much difference; so from the aspect of economics, for making of the geopolymer samples, using the lower molarity $(6 \mathrm{M})$ of sodium hydroxide is preferable. Laterite rock powder with high content of iron oxide in the presence of alumina and silica could be used to produce sustainable, low-cost, and high strength geopolymeric materials.

\section{ACKNOWLEDGMENT}

Hereby, the authors would like to appreciate the supports of the Scientific Student Association Office of the University of Bonab from the student members of the Scientific Student Association of the University to conduct this research.

\section{CONFLICT OF INTEREST}

The authors declare that they have no conflict of interest. 


\section{REFERENCES}

Benhelal, E., et al., 2013. Global strategies and potentials to curb CO2 emissions in cement industry. Journal of cleaner production, 51: p. 142-161.

Gartner, E., 2004. Industrially interesting approaches to "low-CO2" cements. Cement and Concrete research ,9(34) :p. 1489-1498.

McLellan, B.C., et al., 2011. Costs and carbon emissions for geopolymer pastes in comparison to ordinary portland cement. Journal of cleaner production, 19(9-10): p. 1080-1090.

Friedlingstein, P., et al., 2010. Update on CO 2 emissions. Nature geoscience, 3(12): p. 811.

Wong, C.L., et al., 2018. Potential use of brick waste as alternate concrete-making materials: A review. Journal of cleaner production, 195: p. 226-239.

Monteiro, S.N. and C.M.F. Vieira. 2014. On the production of fired clay bricks from waste materials: A critical update. Construction and Building Materials, 68: p. 599-610.

Zhang, L. 2013. Production of bricks from waste materials-A review. Construction and building materials, 47: $\mathrm{p}$. 643-655.

Reddy, B.V. and K. Jagadish. 2003. Embodied energy of common and alternative building materials and technologies. Energy and buildings, 35(2): p. 129-137.

Duxson, P., et al., 2007. Geopolymer technology: the current state of the art. Journal of materials science, 42(9): p. 2917-2933.

Hwang, C.-L. and T.-P. Huynh. 2015. Investigation into the use of unground rice husk ash to produce ecofriendly construction bricks. Construction and Building Materials, 93: p. 335-341.

Davidovits, J. 1991. Geopolymers: inorganic polymeric new materials. Journal of Thermal Analysis and calorimetry, 37(8): p. 1633-1656.

Rovnaník, P. 2010. Effect of curing temperature on the development of hard structure of metakaolin-based geopolymer. Construction and building materials, 24(7): p. 1176-1183.

Djobo, J.N.Y., et al., 2016. Mechanical properties and durability of volcanic ash based geopolymer mortars. Construction and Building Materials, 124: p. 606-614.

Kaze, C.R., et al., 2018. Effect of silicate modulus on the setting, mechanical strength and microstructure of ironrich aluminosilicate (laterite) based-geopolymer cured at room temperature. Ceramics International, 44(17): p. 21442-21450.

Lampris, C., R. Lupo, and C.R. Cheeseman. 2009. Geopolymerisation of silt generated from construction and demolition waste washing plants. Waste Management, 29(1): p. 368-373.

Ahmari, S. and L. Zhang, 2012. Production of eco-friendly bricks from copper mine tailings through geopolymerization. Construction and building materials, 29: p. 323-331.

Yusuf, M.O., et al., 2014. Performance of Different Grades of Palm Oil Fuel Ash with Ground Slag as Base Materials in the Synthesis of Alkaline Activated Mortar. Journal of Advanced Concrete Technology, 12(10): p. 378-387.

Salami, B.A., et al., 2017. POFA-Engineered Alkali-activated Cementitious Composite Performance in Acid Environment. Journal of Advanced Concrete Technology, 15(11): p. 684-699.

Adam, A.A. 2009. Strength and Durability Properties of Alkali Activated Slag and Fly Ash-Based Geopolymer Concrete, RMIT University Melbourne, Australia. 
Maiti, A., et al., 2008. Batch and column study: adsorption of arsenate using untreated laterite as adsorbent. Industrial \& engineering chemistry research, 47 :(5)p. 1620-1629.

Mbumbia, L., A.M. de Wilmars, and J. Tirlocq. 2000. Performance characteristics of lateritic soil bricks fired at low temperatures: a case study of Cameroon. Construction and Building Materials, 14(3): p. 121-131.

Boutterin, C and J. Davidovits, 1988. Geopolymeric cross-linking (LTGS) and building materials. Geopolymer'88, 1: p. 79-88.

Kamseu, E., et al., 2020. Ferrisilicates formation during the geopolymerization of natural Fe-rich aluminosilicate precursors. Materials Chemistry and Physics, 240: p. 122062.

Kaze, R., et al., 2017. The corrosion of kaolinite by iron minerals and the effects on geopolymerization. Applied Clay Science, 138: p. 48-62.

Gualtieri, M.L., et al., 2015. Inorganic polymers from laterite using activation with phosphoric acid and alkaline sodium silicate solution: mechanical and microstructural properties. Cement and Concrete Research, 67: p. 259270.

Kaze, R.C., et al., 2018. Microstructure and engineering properties of Fe2O3 (FeO)-Al2O3-SiO2 based geopolymer composites. Journal of cleaner production, 199: p. 849-859.

Latifi, N., A. Eisazadeh, and A. Marto. 2014. Strength behavior and microstructural characteristics of tropical laterite soil treated with sodium silicate-based liquid stabilizer. Environmental earth sciences, 72(1): p. 91-98.

Latifi, N., 2014. Geotechnical and Micro-Structural Behaviour of Chemically Stabilized Tropical Residual Soil, Universiti Teknologi Malaysia.

Memon, F.A., et al., 2011. Effect of curing conditions on strength of fly ash-based self-compacting geopolymer concrete. Int. J. Civ. Environ. Eng, 3: p. 183-186.

Al Bakri, A.M., et al. 2011. Microstructure of different $\mathrm{NaOH}$ molarity of fly ash-based green polymeric cement. Journal of Engineering and Technology Research, 3(2): p. 44-49.

Mo, B.-h., et al., 2014. Effect of curing temperature on geopolymerization of metakaolin-based geopolymers. Applied clay science, 99: p. 144-148.

Graytee, A., J.G. Sanjayan, and A. Nazari. 2018. Development of a high strength fly ash-based geopolymer in short time by using microwave curing. Ceramics International, 44(7): p. 8216-8222.

Khale, D. and R. Chaudhary. 2007. Mechanism of geopolymerization and factors influencing its development: a review. Journal of materials science, 42(3): p. 729-746.

Abdullah, M., et al. 2011. The relationship of $\mathrm{NaOH}$ molarity, $\mathrm{Na} 2 \mathrm{SiO} 3 / \mathrm{NaOH}$ ratio, fly ash/alkaline activator ratio, and curing temperature to the strength of fly ash-based geopolymer. in Advanced Materials Research. Trans Tech Publ.

Mustafa Al Bakri, A., et al., 2012. Effect of $\mathrm{Na} 2 \mathrm{SiO}$ 3/ $\mathrm{NaOH}$ Ratios and $\mathrm{NaOH}$ Molarities on Compressive Strength of Fly-Ash-Based Geopolymer. ACI Materials Journal, 109.(5)

Budh, C. and N. Warhade. 2014. Effect of molarity on compressive strength of geopolymer mortar. International Journal of Civil Engineering Research, 5(1): p. 83-86.

Gourley, J. and G. Johnson. 2005. Developments in geopolymer precast concrete. in World Congress Geopolymer. Geopolymer Institute Saint-Quentin, France.

Lloyd, N. and V. Rangan. 2010. Geopolymer concrete with fly ash. in Proceedings of the Second International Conference on Sustainable Construction Materials and Technologies, UWM Center for By-Products Utilization. 
Satpute Manesh, B., R. Wakchaure Madhukar, and V. Patankar Subhash. 2012. Effect of duration and temperature of curing on compressive strength of geopolymer concrete. International Journal of Engineering and Innovative Technology (IJEIT) Volume, 1.

Atiş, C., et al. 2015. Very high strength (120 MPa) class F fly ash geopolymer mortar activated at different $\mathrm{NaOH}$ amount, heat curing temperature and heat curing duration. Construction and Building Materials, 96: p. 673-678. 